\title{
LINGUAGEM \\ E FORMAÇÃO \\ DE CONCEITOS: \\ UMA LEITURA \\ A PARTIR DA ESCOLA \\ DE VIGOTSKI
}

\author{
LENGUAJE Y FORMACIÓN DE CONCEPTOS: UNA LECTURA A PARTIR DE LA ESCUELA DE \\ VIGOTSKI
}

LANGUAGE AND CONCEPT DEVELOPMENT: A READING FROM THE VIGOTSKI SCHOOL

\author{
Antonio Dário Lopes Júnior* \\ Betânia Moreira de Moraes** \\ Ruth Maria de Paula Gonçalves*** \\ Universidade Estadual do Ceará
}

RESUMO: O presente estudo é fruto de uma pesquisa de mestrado que objetivou evidenciar, dentro da obra de Vigotski, a importância conferida à linguagem no processo da formação de conceitos. Trata-se de um estudo de natureza teórica, realizado mediante pesquisa bibliográfica, sendo dividido em dois momentos principais. No primeiro, ao retomar o legado marxiano do autor, apresenta-se o papel desempenhado pelas categorias trabalho e linguagem para o processo de formação da consciência. Tal discussão se faz necessária para abordar, no segundo momento, as características da linguagem e como se dá o processo de formação dos conceitos. Tal reflexão servirá de base para sinalizar, à luz da teoria de Vigotski, a importância do professor e da escola no processo de humanização do homem.

PALAVRAS-CHAVE: Vigotski. Linguagem. Formação de conceitos.

RESUMEN: El presente estudio es resultado de una investigación de maestría que buscó evidenciar, dentro de la obra de Vigotski, la importancia conferida al lenguaje en el proceso de la formación de conceptos. Se trata de un estudio de naturaleza teórica, realizado mediante investigación bibliográfica, que se divide en dos momentos principales. En el primero, al retomar el legado marxiano del autor, se presenta el papel desempeñado por las categorías trabajo y lenguaje para el proceso de formación de la

\footnotetext{
* Graduado em psicologia pela Universidade Estadual do Ceará e Mestre em Educaça o pela Universidade Estadual do Ceará. Doutorandoem Educação pela Universidade Estadualdo Ceará. E-mail: adlopesjunior@hotmail.com.

** Professora da Universidade Estadual do Ceará, Centro de Educação, Curso de Pedagogia. Formada em Psicologia, com doutoradoem Educaçãoepós-Doutoradoem PsicologiaSocial. E-mail: betaneamoreas@hotmail.com.

*** Professora da Universidade Estadual do Ceará, Centro de Humanidades, Curso de Psicologia. Formada em Pedagogia, com doutoradoem Educaçãoepós-Doutoradoem PsicologiaSocial. E-mail:depaularuth@gmail.com.
} 
conciencia. Esta discusión se hace necesaria para abordar, en el segundo momento, las características del lenguaje y cómo se da el proceso de formación de los conceptos. Tal reflexión servirá de base para señalar, a la luz de la teoría de Vigotski, la importancia del profesor y de la escuela en el proceso de humanización del hombre.

PALABRAS CLAVE: Vigotski. Lenguaje. Formación de conceptos.

ABSTRACT: The present study is the result of a master's research that aimed to highlight, within Vygotsky's work, the importance given to language in the concept formation process. This is a theoretical study, carried out through bibliographical research, being divided in two main moments. In the first one, when the author's Marxian legacy is retaken, the role played by the categories work and language for the process of formation of consciousness is presented. Such discussion is necessary to approach, in the second moment, the characteristics of the language and how the process of formation of concepts takes place. Such reflection will serve as a basis to signal, in the light of Vygotsky's theory, the importance of the teacher and the school in the humanization process of people. KEYWORDS: Vigotsky. Language. Formation of concepts

\section{INTRODUÇÃO}

As particularidades que conferem a humanidade ao homem têm sido objeto de estudo, tanto da filosofia quanto da psicologia, desde seu surgimento, existindo, assim, diversas maneiras de respondê-la. Algumas tentavam compreender as particularidades do comportamento humano tomando como referência o aspecto de seu desenvolvimento biológico, enquanto outras, tinham como foco, as particularidades da alma. É a partir de Marx, no entanto, que se desvela que o trabalho, enquanto atividade vital consciente e livre, constitui o ato que funda nossa humanidade, evidenciando, assim, a passagem das leis naturais para as leis histórico-sociais como momento predominante na constituição do ser humano.

Segundo o filósofo alemão, o trabalho possui a capacidade de produzir mais do que o necessário para a reprodução do seu produtor, uma vez que seu produto se converte em um material que, mesmo que outrora existisse na natureza, passa a ser adaptado às necessidades humanas, mediante uma mudança de forma, ou seja, é convertido em um meio de produção (MARX, 2014). Apreendemos que esse processo inaugura a complexificação do homem, o qual se depara com os frutos de seu trabalho, o analisa e aperfeiçoa. Assim, a satisfação das necessidades se dá em uma espiral crescente, e a cada volta as necessidades são mais complexas, bem como as formas de sua satisfação (LUKÁCS, 2013; MARX, 2014).

Compreendemos que, por meio do trabalho, o homem transforma a natureza externa, segundo a sua vontade e, concomitantemente a esse processo, modifica também a natureza interna. Não por acaso, ao abordar as funções psicológicas superiores, Vigotski as explicita por meio do uso consciente dos signos, os quais atuam de maneira semelhante ao instrumento de trabalho, cuja diferença reside no fato de que o instrumento estar direcionado à natureza externa, enquanto o signo atua como um vetor da vontade humana sobre outro homem (LOPES JUNIOR; MORAES; GONÇALVES, 2017).

Com efeito, Leontiev (2004) sinaliza que, ao adotarmos a centralidade do trabalho, introduzimos na investigação dos fenômenos psicológicos a concepção de historicidade, por meio da qual o processo de reorganização dos mecanismos naturais se dá em decorrência da evolução sócio-histórica do homem. Para o autor, Vigotski acreditava que tal reorganização seria o resultado necessário da apropriação pelo homem dos produtos da cultura no decurso de seu contato direto com outros representantes do gênero humano.

Destacamos que esse aspecto do pensamento marxiano nos auxilia no sentido de obtermos uma melhor compreensão do caminho trilhado por Vigotski e seu entendimento acerca da natureza do psiquismo humano, além da forma como a linguagem atua no processo de gênese da consciência. Em detrimento das propostas então vigentes, nesta, a história acaba por ser considerada enquanto a força motriz para o desenvolvimento. Nesse contexto, as proposições de sua época, radicadas no idealismo e no positivismo, acabam obscurecendo o problema em questão, ou pela negação da importância que o desenvolvimento cultural tem no desenvolvimento das funções psicológicas superiores, do tornar-se homem do homem, enquanto a outra dilui a história humana no percurso de desenvolvimento do espírito (VYGOTSKI, 2012). Em suma, consoante Luria (1991), as raízes da atividade

Lopes Júnior, Moraes \& Gonçalves / Linguagem e formação de conceitos: uma leitura a partir da escola de Vigotski 
consciente do homem não deveriam ser procuradas nas peculiaridades da alma, nem no íntimo dos organismos, mas nas condições sociais de vida historicamente formadas.

Assim, temos a gestação de uma proposta que se contrapõe às imperantes, uma vez que, para se estudar a consciência, faz-se necessário compreender o homem, seu modo de vida, sua existência (LEONTIEV, 2004), suas particularidades sendo gestadas na tessitura das relações historicamente produzidas pelo conjunto dos homens, as quais encetam a modificação da estrutura de sua própria atividade.

Dito isso, a proposta deste estudo é demonstrar, dentro do arcabouço teórico da Escola de Vigotski, o papel da linguagem na gênese/processualidade da consciência, tendo o trabalho como ato-gênese do ser social, a fim de destacar o processo de formação de conceitos.

\section{TRABALHO, LINGUAGEM E A FORMAÇÃO DA CONSCIÊNCIA}

Antes mesmo de iniciarmos de maneira pormenorizada nossas formulações sobre as particularidades da linguagem, frisamos que coube a Engels (1983) postular de forma coesa, a real e justa medida da vinculação entre as duas categorias, Trabalho e Linguagem, aquele ocupando o primeiro lugar na relação entre fundante e fundado. O autor assinala que, em primeiro lugar é o trabalho "[...] e depois dele, e em seguida a par com a linguagem são os dois incentivos mais importantes sob cuja influência tem gradualmente transformado o cérebro do macaco no cérebro do homem, que, apesar de ser como ele, é muito maior e mais perfeito. " (ENGELS, 1983, p. 146, tradução livre).

Ao retomar esse postulado, Leontiev (2004) esclarece que a primazia do trabalho se refere ao fato dele servir como elemento de ligação entre o homem e a natureza, no qual se articulam a confecção dos instrumentos que ocorre mediante a atividade comum coletiva, por meio da qual, o homem “[...] não entra em uma relação determinada com a natureza, mas com outros homens." (LEONTIEV, 2004, p. 80).

Sinalizamos, assim, que o desenvolvimento da linguagem se configura como a segunda condição fundamental que levará ao desenvolvimento da atividade consciente do homem (LURIA, 1991). Tal afirmação não se refere a uma gradação cronológica. Na compreensão marxiana, ser primeiro ou fundante não significa ser anterior, mas portador das determinações essenciais que constituirão o ser social (LUKÁCS, 2013). Nesse sentido, primeiro temos o trabalho, a transformação da natureza mediada pela sociabilidade, depois, mediante a criação do produto, temos a linguagem, através da qual os demais membros de determinado grupo social se apropriam daquilo que foi produzido. Em outros termos, o trabalho pode ser compreendido enquanto a potência criadora, e a linguagem atuando como uma via primeira para a apropriação desta criação.

De acordo com Marx e Engels (2007, p. 53), a linguagem pode ser considerada tão antiga quanto a consciência: "[...] a linguagem é a consciência prática, a consciência real, que existe também para os outros homens e que, portanto, começa a existir também para mim mesmo; e a linguagem nasce, assim como a consciência, da necessidade, da carência de intercâmbio com os demais homens".

Com efeito, a função da linguagem, por excelência, é a comunicação. Para Vigotski (2009, p. 11), ela é “[...] antes de tudo, um meio de comunicação social, de enunciação e compreensão”, sendo composta por um sistema de códigos, por meio dos quais é possível designar objetos, ações, qualidades e as possíveis inter-relações entre quaisquer desses aspectos. Com ela o homem consegue transmitir as informações assimiladas por meio da experiência acumulada pelas gerações precedentes (LURIA, 1991).

Convém destacar que a linguagem é uma faculdade humana, inexistindo nos demais animais, surgindo na transição da animalidade para a sociedade humana. Nas demais espécies do reino animal não percebemos o emprego sistematizado dos signos, aos quais

${ }^{1}[$...] y después de él y enseguida a la par con él el lenguaje son los dos incentivos más importantes bajo cuya influencia se ha transformado paulatinamente el cerebro del mono en el cerebro del hombre, que, aun - siendo semejante a él, es mucho mayor y más perfecto. 
comporão o sentido da palavra, do símbolo, da linguagem, tendo em vista que "[...] sem significado a palavra não é palavra, mas som vazio. Privada do significado, ela já não pertence ao reino da linguagem." (VIGOTSKI, 2009, p. 10). Assim, se forçarmos um entendimento de uma "linguagem" animal, esta nunca designa coisas, não distingue ações, nem qualidades, podendo ser considerada como um epifenômeno do ser orgânico, por meio da qual o animal experiente, ao perceber o perigo emite algum som gutural para o resto do bando, ele não comunica aos demais membros o que viu, não se utiliza dos signos, mas os contagia com a sensação que teve ao ver o potencial perigo, sendo esse processo uma das formas mais primitivas de comunicação. Nesse sentido:

[...] a comunicação, estabelecida com base em compreensão racional e na intenção de transmitir ideias e vivências, exige necessariamente um sistema de meios cujo protótipo foi, é e continuará sendo a linguagem humana, que surgiu da necessidade de comunicação no processo de trabalho. (VIGOTSKI, 2009, p. 11, grifo nosso)

Evidenciamos, assim, que o trabalho gesta um distanciamento real entre o sujeito e o objeto, o qual passa a ser comunicável por meio da linguagem se convertendo em um patrimônio da sociedade.

A esse respeito, Lukács (2013, p. 127, grifo do autor), ao retomar os postulados de Engels, advoga que o distanciamento das barreiras naturais cria a base imprescindível, "[...] dotada de vida própria, do ser social dos homens: a linguagem. [...] os homens tinham algo para dizer um ao outro. A necessidade cria seu órgão correspondente.”. E continua afirmando que:

O homem sempre fala "sobre" algo determinado, que ele extrai de sua existência imediata em um duplo sentido: primeiro, na medida em que isso é posto como objeto que existe de maneira independente, segundo - e aqui a distância aparece ainda mais intensamente, se isso é possível -, empenhando-se por precisar cada vez o objeto em questão como algo concreto; seus meios de expressão, as suas designações são de tal modo constituídos que cada signo pode figurar em contextos completamente diferentes. Desse modo, a reprodução realizada através do signo linguístico se separa dos objetos designados por ele e, por conseguinte, também do sujeito que o expressa, tornando-se expressão intelectual de um grupo inteiro de fenômenos determinados, que podem ser aplicados de maneira similar por sujeitos inteiramente diferentes em contextos inteiramente diferentes. (LUKÁCS, 2013, p. 127 , grifo nosso)

A palavra em si passa a não se referir a um objeto isolado, mas a toda uma classe de objetos e "[...] por essa razão, cada palavra é uma generalização latente, toda palavra já generaliza e, em termos psicológicos, é antes de tudo uma generalização." (VIGOTSKI, 2009, p. 9), a qual só faz sentido para aqueles que compactuem do significado dos códigos linguísticos de determinado grupo. Não por acaso, diversos povos primitivos foram designados por estrangeiros como mudos, por serem incapazes de se comunicar (LUKÁCS, 2013).

Ao se debruçar sobre os estudos a respeito da linguagem, Luria (1991) demonstra que, de maneira semelhante ao que ocorre no problema da atividade consciente do homem, a linguagem também é objeto de inúmeras hipóteses e teorias, entre as quais podemos destacar algumas que consideram a linguagem como uma manifestação do campo espiritual, atribuindo-lhe uma origem quase divina.

Para Luria (1991), tais teorias são muito vagas e omitem o fato de que a linguagem é em especial, uma forma simbólica de existência. Outras teorias, por outro lado, ao se filiarem a tradições naturalistas, tendem a considerar a linguagem como fruto da evolução biológica, interpretando como formas primitivas de linguagem as formas de comunicação dos animais. Seguindo a perspectiva do autor, destacamos que tais concepções são marcadas por um reducionismo, o qual não auxilia uma compreensão mais detalhada acerca da linguagem.

Luria (1991, p. 79, grifo do autor) vê como necessária a busca de sua origem, não em um aspecto espiritual, ou as particularidades da atividade cerebral, mas perceber que "[...] as condições que originam o fenômeno devem ser procuradas nas relações sociais de trabalho, cujos primórdios de surgimento remontam ao período de transição da história natural à história humana", uma vez que, ao fazer frente às proposições biologizantes, sinalizamos que um desenvolvimento não pode ser tido como a simples continuação direta de outro, como se da experiência do contágio vivenciada pelos animais estivessem os rudimentos da linguagem humana, ao se 
relacionar essas duas esferas frisamos a existência de um salto, materializado pela mudança do "[...] próprio tipo de desenvolvimento - do biológico para o histórico-social." (VIGOTSKI, 2009, p. 149, grifo do autor).

Em consonância com os escritos do autor soviético, sinalizamos com Lukács (2013) que, de maneira semelhante ao que ocorre com a categoria Trabalho, a Linguagem também se consumou no feitio de um salto da dimensão natural para a social. No entanto, retomamos que ao tratar de um salto, o percebemos enquanto um processo lento, cheio de idas e vindas, "[...] cujos primeiros começos permanecerão desconhecidos para sempre, ao passo que, com a ajuda do desenvolvimento das ferramentas, podemos estudar e, dentro de certos limites, abarcar" (LUKÁCS, 2013, p. 129) a posteriori o conjunto de sua orientação e desenvolvimento.

Ao tentarmos nos apropriar das características da linguagem, consideramos que suas funções primordiais não residem em seu caráter fônico ou se expressam por meio de palavras, mas sim pelo emprego funcional do instrumento psicológico, do signo, o qual corresponde ao processo de fala humana (VIGOTSKI, 2009). Como instrumento psicológico, as características da linguagem vão sendo paulatinamente alteradas, desenvolvendo-se em decorrência de sua utilização e das necessidades que surgem do incremento da vida em sociedade, gerando certo refinamento em sua estrutura geral. Consoante Lukács (2013), a linguagem se desenvolverá de forma ininterrupta, em virtude de sua relação com o trabalho, a divisão do trabalho e a cooperação, tornando sua estrutura cada vez mais rica e maleável, na medida em que a complexificação do processo de trabalho necessita ser comunicada.

Nesse sentido, coube a Luria $(1986,1991)$, um dos seguidores de Vigotski, evidenciar o processo de desenvolvimento da linguagem no gênero humano. Segundo o autor, em um primeiro momento, a palavra estava estritamente enlaçada com a prática, isolada desta não teria uma verdadeira existência independente, só sendo possível compreender o seu significado dentro da situação em que esta surgiu, a palavra possuía um caráter simpráxico. Em um segundo momento, depois de milhares de anos de aperfeiçoamento desse instrumento, a palavra se emancipa do terreno da prática, virando um sistema autônomo de signos, os quais necessitam apenas uns dos outros para serem compreendidos, passando a figurar em um sistema sinsemântico.

Dentro do arcabouço teórico da psicologia histórico-cultural, a linguagem se constitui em uma das funções psicológicas superiores que têm por característica principal o fato de serem processos que incorporam à sua estrutura, como parte central de todo o processo, o emprego de um signo enquanto meio principal para a orientação e o concomitante domínio dos processos psíquicos (VIGOTSKI, 2009). Vale ressaltar que a utilização dessa faculdade opera uma profunda reorganização na atividade consciente do homem, imprimindo nesta ao menos três mudanças básicas.

Em primeiro lugar, reiteramos a importância que a palavra tem para o afastamento entre sujeito e objeto gestado pelo processo de trabalho, o qual consiste na unidade e não identidade, os quais ganham certas especificidades que só fazem sentido por meio do contato social. Ao se denominar objetos, ou os fenômenos do mundo exterior com uma palavra ou um conjunto delas, é possível discriminar esses objetos, dirigir a atenção sobre eles e conservá-los na memória. Assim, o homem consegue se relacionar com tais objetos mesmo em sua ausência (LURIA, 1991), ocorrendo a criação de um protoconceito. Para Vigotski (2009), no processo de formação de conceitos o signo é a palavra que tem, em princípio, papel de meio para a formação de um conceito e, posteriormente, converte-se em seu símbolo.

Em segundo lugar, por meio da linguagem, deslocamos nossa atenção para determinado tipo de objeto. Nesse processo, não apenas o discriminamos como um ser em si, como também atribuímos a ele certo valor e funcionalidade, ou seja, abstraímos as propriedades essenciais destes objetos, ao relacionar as diversas dimensões perceptíveis em categorias. Para Luria (1991, p. 80, grifos do autor), tal possibilidade de assegurar o "processo de abstração e generalização representa a segunda contribuição importantíssima da linguagem para a formação da consciência.".

O signo linguístico se converte em um meio para a análise e classificação de objetos e fenômenos, os quais se formam ao longo de toda a história social da humanidade. Esse fato confere à linguagem a possibilidade de se converter não apenas em um meio para a comunicação - sua principal função -, como também em um veículo para o pensamento, assegurando a transmissão do sensorial ao racional, no que concerne à percepção do mundo sensível. 
Fundamentado nas prerrogativas acima apontadas, Luria (1991) advoga que por essas duas características, a linguagem se destaca como o principal veículo para a transmissão da informação, ou seja, a terceira via para o desenvolvimento da consciência, a qual consiste na apropriação da experiência acumulada sócio-historicamente, dos instrumentos e das formas de se relacionar com a natureza modificada pelo trabalho. A linguagem pode ser considerada como um instrumento mediador, pois auxilia o indivíduo a:

[...] dominar um ciclo imensurável de conhecimentos, habilidades e modos de comportamento, que em hipótese alguma poderiam ser resultado da atividade independente de um indivíduo isolado. Isto significa que com o surgimento da linguagem surge no homem um tipo inteiramente novo de desenvolvimento psíquico desconhecido dos animais, e que a linguagem é realmente o meio mais importante para o desenvolvimento da consciência. (LURIA, 1991, p. 81, grifo do autor)

Ancorada nessa concepção, Martins (2016) advoga que apenas por meio da linguagem é possível a abstração das propriedades, condicionantes, características da situação-problema ou da tarefa a ser realizada, o que auxilia em sua formulação sob a forma de ideias, conceitos ou juízos. Para a autora, a linguagem "[...] possibilita o raciocínio sistematizado, o exercício intelectual de checagem das conexões entre os objetos e fenômenos da realidade e suas propriedades essenciais." (MARTINS, 2016, p. 1574).

Por meio da linguagem o indivíduo consegue se apropriar da riqueza historicamente acumulada, ou seja, dos instrumentos e signos gestados pelas gerações anteriores, devendo, em seu processo de humanização se apropriar de tal legado, ocorrendo mediante o contato com outrem.

Esse preâmbulo foi necessário para que tenhamos os fundamentos teóricos que nos permitirão seguir, tomando como norte a psicologia histórico-cultural. Assim, é por meio da apropriação da linguagem e dos signos socialmente constituídos que o ser humano se apropria das ferramentas necessárias para compreender o mundo. Diante do que apresentamos anteriormente, nos passos seguintes de nossa proposta tentaremos abordar, de forma sucinta, como se desenvolve a lente que auxilia os homens a conhecer o mundo em suas mais diversas formas: os conceitos.

\section{LINGUAGEM E A FORMACÃO DE CONCEITOS}

O processo de formação dos conceitos não ocorre de uma maneira passiva, por meio do simples vínculo associativo entre um determinado estímulo e a resposta, como nos animais. O domínio do conceito pode ser correlato ao domínio da palavra, ou do signo, por meio do qual o indivíduo passa a estar apto a se afastar dos ditames impostos por sua natureza biológica, subordinando o seu comportamento à sua própria vontade.

Nesses termos, acerca da relação entre a linguagem e a formação de conceitos, Vigotski (2009, p. 170, grifo nosso) esclarece que: "O conceito é impossível sem palavras, o pensamento em conceito é impossível fora do pensamento verbal; em todo esse processo, o momento central, que tem todos os fundamentos para ser considerado causa decorrente do amadurecimento de conceitos, é o emprego específico da palavra, o emprego funcional do signo como meio de formação de conceitos".

Sendo o signo uma estrutura social, no âmbito das discussões que permeiam a prática pedagógica nos opomos a propostas que defendam a preponderância da maturação biológica para o desenvolvimento do indivíduo, levando em consideração que o conceito se constitui por uma via de desenvolvimento ulterior, radicada fora do indivíduo. Dessa maneira, os problemas que o meio social coloca para esse indivíduo em processo de formação, vinculados à projeção deste, quer em um aspecto pessoal, profissional ou cultural se constituirão de uma amálgama que terá por função “[...] reiterar o intercondicionamento, a conexão orgânica e a unidade interna entre os momentos do conteúdo e da forma no desenvolvimento do pensamento." (VIGOTSKI, 2009, p. 171).

Por outro lado, em ambientes que não ofereçam aos sujeitos problemas correspondentes não se aumentam as exigências ou, ainda, o grau de abstração necessária para a solução dos problemas existentes; dessa maneira, o ser humano não conseguirá desenvolver as formas superiores de conduta, ou as atingirá com um considerável atraso.

Lopes Júnior, Moraes \& Gonçalves | Linguagem e formação de conceitos: uma leitura a partir da escola de Vigotski 
Esse processo de atraso no desenvolvimento de determinadas faculdades humanas está vinculado a aspectos de ordem social, ou mesmo de acesso ao conhecimento socialmente constituído, é claro. Contudo, faz-se necessário explicitar essa relação, tendo em vista que, conforme Duarte (2016), existia na época de Vigotski, e também na atualidade, várias teorias psicológicas e pedagógicas que concebiam o desenvolvimento psíquico como um processo autoproduzido, ou seja, radicado na esfera biológica.

Convém destacar que uma das especificidades da esfera educativa, dentro dos postulados de Vigotski, caracteriza-se por apresentar à criança e ao adolescente a cultura e a riqueza socialmente acumulada, elevando as exigências sociais para o desenvolvimento das potencialidades humanas. Em outros termos, o processo educativo é demarcado pela incorporação, por parte da criança/adolescente, dos sistemas de instrumentos psicológicos às suas atividades socialmente constituídas, gerando o desenvolvimento psíquico (VIGOTSKI, 2009; FACCI, 2004; DUARTE, 2016).

Uma vez considerados como o entrelaçamento entre as esferas do pensamento e da linguagem, os conceitos se configuram como generalizações da realidade sensível. Nesse sentido, Martins (2016) advoga que os estudos de Vigotski sobre o desenvolvimento do indivíduo e das estruturas de generalização, passam a conferir características específicas à formação de conceitos, que segue três estágios básicos: pensamento sincrético, pensamento por complexos e pensamento conceitual.

O primeiro se caracteriza pela formação de uma pluralidade não informada e não ordenada, momento no qual a criança se depara com um amontoado de objetos, no entanto, ainda não tem os recursos para discriminá-los, mas os adultos que com ela interagem podem auxiliá-la, apresentando um novo conceito. Para Vigotski (2009), nesse momento, o significado da palavra corresponde a um encadeamento sincrético não ordenado de objetos particulares, que nas representações infantis são concatenados em uma imagem mista.

Vigotski (2009) reconhece que nesse estágio a ação da criança revela uma tendência a associar, a partir de uma única impressão para designar os mais diversos elementos presentes no objeto, fundindo-os em uma imagem que não pode ser desdobrada. Simplificando, é como se a criança substituísse a carência de nexos objetivos por uma superabundância de nexos subjetivos, uma vez que confunde a relação entre as impressões e o pensamento com a relação entre os objetos.

Contudo, por meio de Martins (2016) sinalizamos que nessa fase a criança conquista o domínio do aspecto denominativo da palavra, o que lhe permite o desenvolvimento da fala compreensível. Porém, vale ressaltar que ainda não existe correspondência direta entre os aspectos fonético e semântico da palavra. No entanto, o significado atribuído à criança para algumas palavras pode condizer com o significado para o adulto, as quais facilitarão o seu processo de comunicação.

Na segunda fase desse estágio, de acordo como os estudos vigotskianos, as leis puramente sincréticas da percepção, do campo visual e a organização da percepção da criança desempenham um papel decisivo. Tal formação se configura na base para as relações espaciais e temporais de determinados elementos do cotidiano imediato.

Nas palavras de Vigotski (2009, p. 177), nessa fase, o essencial é que a criança não se oriente pelos vínculos objetivos, mas pelos vínculos subjetivos que sua percepção lhe sugere, "[...] os objetos se aproximam em uma série e são revertidos de significado comum, não por força dos seus próprios traços destacados pela criança, mas da semelhança que entre eles se estabelece na impressão da criança.”. Vislumbramos, assim, os primeiros indícios de uma organização do campo perceptual. Os agrupamentos ainda se configuram pelo aspecto sincrético, no entanto, agora passam a levar em conta a contiguidade espacial e temporal de seus elementos (MARTINS, 2016).

Já a terceira fase corresponde ao momento em que a imagem sincrética corresponde a um conceito, formando-se a partir de uma base mais complexa e se apoia na atribuição de um único significado aos representantes dos diferentes grupos, aqueles unificados pela percepção da criança.

O segundo estágio, para Vigotski (2009), conduz à formação de vínculos, ao estabelecimento de relações entre as diferentes impressões concretas e à unificação e generalização de objetos particulares. Daí percebemos que tal estágio encontra íntima relação 
com a segunda característica da linguagem, a qual consiste nos processos de generalização e abstração, uma vez que, no desenvolvimento da criança, esse estágio corresponde ao processo de ordenamento e sistematização da experiência por parte dela. Para Martins (2016), essa fase seguirá um longo percurso no desenvolvimento do indivíduo, compreendendo o processo de formação de conceitos desde o término da primeira infância até o início da adolescência, perpassando por várias modificações funcionais e estruturais.

Assim, se o estágio anterior era marcado pela construção de imagens sincréticas, que na criança equivale aos nossos conceitos, o segundo, o pensamento por complexos, se caracteriza pela construção de complexos que têm o mesmo sentido funcional, embora suplante o estágio anterior.

A este respeito Vigotski (2009) esclarece que, a passagem do pensamento sincrético para o complexo ocorre quando ao invés de ter um "nexo desconexo", baseado na imagem sincrética, a criança começa a unificar os objetos homogêneos em grupos comuns, por meio do reconhecimento de vínculos objetivos que ela descobre em tais objetos. Assim, o pensamento por complexo, em detrimento do anterior, já é coerente e objetivo.

Para o autor, o mais importante em se compreender o aspecto do complexo e sua diferenciação do conceito propriamente dito, reside no fato de o primeiro ter em sua base "[... não um vínculo abstrato e lógico mas um vínculo concreto e fatual entre elementos particulares que integram a sua composição." (VIGOTSKI, 2009, p. 180). O complexo está radicado nos vínculos factuais da experiência imediata, representando uma unificação concreta de um grupo de objetos, tomando por base a sua semelhança física. No pensamento conceitual, por outro lado, os objetos passam a ser generalizados por meio de um determinado traço que não tem necessariamente relação com um vínculo concreto.

Dito isso, convém destacar que o pensamento por complexo também pode ser subdividido em alguns momentos, a saber: complexo associativo, por coleção, por cadeia, complexos difusos e pseudoconceitos

O primeiro momento (complexo associativo) se baseia em qualquer vínculo associativo, com algum traço observado pela criança no objeto, podendo este se converter no núcleo do complexo. Com efeito, qualquer relação concreta, descoberta pela criança, ou seja, as mais diversas relações associativas entre o núcleo e o objeto já são é o suficiente para que a criança o inclua no grupo (VIGOTSKI, 2009), objetos que tenham cores semelhantes, ou formas, mesmo que sejam diferentes, qualquer coisa que chame a atenção da criança.

O segundo momento do pensamento por complexo consiste na combinação de objetos e impressões concretas em grupos especiais de fenômenos, comumente chamados de coleções, nos quais os diferentes elementos concretos se combinam com base em uma complementação mútua, formando um todo constituído a partir de partes heterogêneas (VIGOTSKI, 2009).

Para o autor, a diferença principal entre a forma de pensamento por complexos em relação ao pensamento associativo consiste no fato da não inclusão na coleção de exemplares repetidos. Entre os vários grupos se incluem os exemplares únicos para representarem todo um grupo de objetos. Ao invés de sinalizarmos uma associação por semelhança, percebemos uma associação por contraste.

Assim, se as imagens sincréticas se baseiam em vínculos emocionais e subjetivos entre as impressões que a criança confunde com seus objetos, o complexo associativo encontra substrato na semelhança recorrente entre os traços de determinados objetos. A coleção, por outro lado, está radicada nos vínculos e relações de objetos estabelecidos por meio da experiência prática, efetiva e direta da criança. Com efeito, o pensamento por coleção se baseia nos vínculos objetivos que são estabelecidos entre a criança e o seu meio social. É importante ressaltar que a partir daí ocorre o caminho para uma posterior sistematização de impressões difusas a um processo de maior refinamento e organização. No entanto, no pensamento por complexo ainda não existe uma distinção entre os traços da coleção (VIGOTSKI, 2009).

O quarto momento se configura no complexo em cadeia, o qual se constitui por meio da combinação dinâmica e temporal de determinados elos em uma cadeia única de transmissão do significado por meio de elos isolados. A título de exemplo, Vigotski

Lopes Júnior, Moraes \& Gonçalves / Linguagem e formação de conceitos: uma leitura a partir da escola de Vigotski 
(2009) apresenta um experimento no qual mostra à criança um triângulo amarelo, que podemos dividir em dois estímulos: a forma geométrica e a cor. Enquanto a atenção está voltada para a forma, a criança vai juntando várias figuras de forma triangular até que sua atenção seja dirigida a outro estímulo: a cor. Nesse momento, a criança passa a aglomerar várias formas diferentes, com a mesma cor. Relembramos que essa é uma característica do complexo, o vínculo se dá por um aspecto objetivo, em que a discriminação, em virtude do tempo, passa de um traço a outro. Nas palavras de Vigotski (2009, p. 186):

\footnotetext{
Mais uma vez o complexo se baseia no vínculo associativo entre elementos concretos particulares, mas agora esse vínculo associativo não deve ligar necessariamente cada elo isolado com a amostra. Cada elo, ao inserir-se no complexo, torna-se membro isônomo desse complexo como a própria amostra, e mais uma vez, pelo traço associativo, pode tornar-se o centro de atração para uma série de objetos concretos.
}

Por meio desse excerto, reconhecemos que o pensamento por complexo é de natureza eminentemente concreta e figurada. No pensamento por complexo não ocorre a abstração de um determinado traço em detrimento dos demais e, assim, não desempenha nenhum papel específico em detrimento dos demais. Desse modo, no complexo não existe um vínculo hierárquico entre os traços, todos são essencialmente iguais em seus vínculos funcionais.

Ao diferenciar o pensamento por complexo, dos conceitos propriamente ditos, Vigotski (2009, p. 187, grifos nossos) exorta que: "[...] à diferença do conceito, o elemento concreto integra o complexo como unidade real direta com todos os seus traços e vínculos fatuais. O complexo não se sobrepõe aos seus elementos como o conceito se sobrepõe aos objetos concretos que o integram. O complexo se funde de fato aos elementos concretos que o integram e que estão interligados".

O fato é que os vínculos entre os elementos se transformam imperceptivelmente uns nos outros, sendo modificado o próprio tipo de vínculo. Com efeito, a aproximação dos traços é estabelecida tanto com base em sua efetiva semelhança, quanto na impressão vaga e distante de certa identidade entre eles, preparando assim o caminho para o novo momento, os complexos difusos.

A característica essencial que distingue esse quarto momento dos anteriores é que o próprio traço combina, por vias associativas, os elementos concretos particulares, o que o torna difuso, diluído, indefinido. Assim, esse complexo combina, através dos vínculos difusos e indefinidos, os grupos diretamente concretos e imagens ou objetos (VIGOTSKI, 2009).

Compreendemos que o principal incremento funcional do complexo difuso se refere a um caminho rumo à abstração. Se no complexo por coleção predominam as generalizações baseadas em vínculos objetivos, na semelhança funcional o complexo difuso, por outro lado, é baseado precisamente nos campos do pensamento que não se prestam a uma comprovação prática, "[...] noutros termos, nos campos do pensamento não-concreto e não-prático.” (VIGOTSKI, 2009, p. 189).

Ao retomar essa perspectiva, Martins (2016) assinala que os complexos difusos são formados ainda sob os limites das relações visuais concretas e reais entre objetos singulares, contudo, no processo de associação, unem elementos alheios ao conceito prático da criança, resultando em relações estabelecidas por ela livremente e baseadas, muitas vezes, em atributos errôneos.

Todo esse caminho foi necessário para que possamos adentrar no último momento do pensamento por complexos, o qual corresponde aos pseudoconceitos, os quais são formados mediante as generalizações que, muito embora na aparência externa, assemelham-se aos conceitos propriamente ditos, na essência, sua estrutura resulta diferente (MARTINS, 2016). Observa-se que o processo de generalização poderia surgir tomando por base um conceito, a utilização funcional do signo, mas ainda está submetida aos ditames do pensamento por complexo, dos traços concretos.

Percebam que o desenvolvimento dessa forma de atuação por parte da criança não se dá exclusivamente através de sua maturação biológica ou por algum tipo de propriedade espiritual específica da criança, muito pelo contrário, para Vigotski (2009), o desenvolvimento dos complexos infantis não ocorre de forma espontânea, mas se dá por meio da apropriação que a criança faz da palavra usada pelo adulto, que se configura como uma forma de materialização no individual de uma relação que é social. 
Podemos assinalar que é por meio da comunicação verbal, da linguagem, que o adulto pode determinar o caminho por onde irão se desenvolver os processos de generalização. Assim, embora, a criança não copie ipsis litteris o modo de pensar, de compreender o mundo do adulto, deste, ela assimila os significados prontos das palavras, bem como um protótipo da forma em que pode relacionar os complexos. Nessa conjectura, o indivíduo, antes de ter o domínio de determinado conceito começa a utilizá-lo, em virtude da prática social. Para Vigotski (2009, p. 198-199): "O conceito "em si" e "para os outros" se desenvolve na criança antes que se desenvolva o conceito "para si". O conceito "em si" e "para os outros", já contido no pseudoconceito, é a premissa genética básica para o desenvolvimento do conceito no verdadeiro sentido da palavra”.

Com efeito, antes que a criança possa se apropriar da definição verbal dos conceitos, eles são apresentados a ela pelo adulto, os quais vão atuar na mediação com a realidade com relativa independência. Para Martins (2016, p. 1583), o processo de superação dessa condição, e o concomitante avanço dos conceitos potenciais em direção aos conceitos propriamente ditos "resulta do ato real do pensamento por via das operações racionais, fundamentalmente por meio de análises e sínteses cada vez mais elaboradas". Para que este processo consiga ser concluído é necessário, por parte da criança, a construção de abstrações por meio da generalização dos atributos essenciais de seus conceitos potenciais.

Antes de adentrar no processo de formação de conceitos propriamente dito, devemos destacar que, embora a criança tenha aprendido a ligar com as formas superiores de pensamento (os conceitos), não abandona as formas elementares. Mesmo o adulto pode ainda utilizar o pensamento por complexo e mesmo níveis primitivos (VIGOTSKI, 2009). Assim, Vigotski (2009) destaca que, se os conceitos utilizados pelo adolescente não transcendem a esfera da sua experiência cotidiana, ficam estagnados ao nível de pseudoconceitos, complexos, por não passarem de noções gerais sobre aspectos da realidade aparente.

Para Vigotski (2009), o pensamento por complexo se constitui na primeira raiz para a formação dos conceitos, quando a criança complexifica os objetos que percebe, combinando-os em determinados grupos. No entanto, o conceito não supõe apenas a combinação e generalização dos traços dos elementos concretos, pressupõe também a abstração, isolamento de determinados elementos e sua capacidade de análise, os quais deverão ser abstraídos de fora da experiência imediata/concreta. Sendo assim, a primeira fase do terceiro estágio para a formação do conceito pressupõe o desenvolvimento da capacidade para a decomposição, análise e abstração.

Ao relacionar esse momento com o último estágio do pensamento por complexo, o pseudoconceito, Vigotski (2009) advoga que as generalizações criadas pela criança, são, ao mesmo tempo, mais ricas e mais pobres que o pseudoconceitos. Mais ricas, pois sua abstração se baseia em uma discriminação importante e essencial dos traços perceptíveis do grupo geral. Ao mesmo tempo são mais pobres, pois os elos em que essa ligação se baseia são vinculados a uma impressão vaga.

Vigotski (2009) nomeia a segunda fase dessa etapa de estágio de conceitos potenciais. Nela, a criança costuma destacar um grupo de objetos e, depois de reunidos, generaliza o grupo mediante um atributo comum, o qual, mais uma vez encontra estreita semelhança com os pseudoconceitos. No entanto, o autor exalta que suas naturezas são essencialmente diferentes. Ao retomar os estudos de Groos, Vigotski (2009) postula que o conceito potencial se configura como uma formação pré-intelectual, surgindo muito cedo no desenvolvimento do pensamento da criança.

Ao se relacionar com a abstração, exortamos que a diferença básica entre esse estágio com o do pensamento por complexo, reside do fato de que o atributo que serve para a inclusão dos objetos em determinado grupo comum, constitui uma característica privilegiada, abstraída do grupo concreto de uma série de características as quais esse objeto está efetivamente vinculado.

Com efeito, para os autores vinculados à Escola de Vigotski, o verdadeiro conceito surge quando uma série de atributos são abstraídos e sintetizados, por meio do qual se gera uma síntese abstrata que "[...] assim obtida se torna forma basilar de pensamento com o qual a criança percebe e toma conhecimento da realidade que a cerca. Neste caso, o experimento mostra que o papel decisivo na formação do verdadeiro conceito cabe à palavra." (VIGOTSKI, 2009, p. 226). 
Conforme Luria (1991) e Lukács (2013), a linguagem auxilia no processo de reprodução social, uma vez que esta se configura como o único complexo social capaz tanto de atuar no processo de mediação do homem para com a natureza, quanto dos homens entre si (LIMA; JIMENEZ, 2011), sendo considerada uma teleologia secundária.

Sinalizamos, assim, que é a linguagem (a palavra) que carrega consigo o signo, o qual se assemelha ao instrumento de trabalho, e pode ser utilizado nas mais diversas operações intelectuais, as quais passam a ser mediadas pela palavra. Dito de outro modo, a utilização funcional da palavra é uma das características fundamentais que levará a distinção entre o pensamento por complexo do conceito.

Na esteira das proposições de Lukács (2013), retomadas por Lima e Jimenez (2012), é possível assinalar que a linguagem, por meio do processo da educação, exerce uma função primordial para a reprodução do ser social.

Ao retomar as particularidades do processo de reprodução, Lukács (2013), identifica que esta apresenta certa similaridade com a reprodução em termos biológicos, uma vez que é responsável por manter a existência de uma espécie. No entanto, diferente desta, que está pautada nos aspectos biológicos, o processo de reprodução do ser social, embora tenha como base também a natureza, é uma natureza diferente, humanizada pela ação do homem, palco no qual o processo de reprodução/humanização ocorre. Assim, o homem passa a deixar de "encontrar as condições de sua reprodução 'prontas' na natureza, criando-as ele próprio através da práxis social humana." (LUKÁCS, 2013, p. 171). Por meio das assertivas de Lukács (2013), sinalizamos que neste excerto o termo "natureza" se apresenta como um conceito de valor, designando a intenção espontânea e voluntária do homem de realizar, em si, as determinações do gênero humano.

Nesse sentido, enquanto os animais estão afeitos a sua natureza biológica, o homem se relaciona com os ditames de uma natureza mutante, social. Assim, as peculiaridades inerentes ao ser social e a sua forma de reprodução enquanto gênero podem ser vistas permeadas pelo complexo da educação, que, para Lima e Jimenez (2011), consiste na mediação entre a individuação e a generalidade. $\mathrm{O}$ aspecto social a ela inerente é marcado por uma das especificidades da esfera ontológica a qual o ser humano pertence. Por meio de Gonçalves e Jimenez (2013), sinalizamos que, na esfera orgânica, na qual a reprodução se refere à reposição do mesmo, novos seres, ou criações incrustadas pela esfera biológica, as abelhas, castores, os animais sempre se reproduzem e produzem algo semelhante ao que já existia, no ser social, por outro lado, ocorre a produção sempre de um novo, uma vez que o homem se defronta com sua produção e a pode modificar. A sociabilidade não pode ser vista enquanto um processo estático, mas produzida pelo conjunto dos homens em seu eterno devir.

Com efeito, ao pensarmos no conceito propriamente dito, este poderá ser alcançado a partir da adolescência, tendo em vista que nessa fase o ser humano pode ter exigências sociais mais complexas, para as quais as respostas dadas por suas experiências cotidianas já não lhe proporcionem as respostas. Se os problemas postos aos adolescentes e adultos se restringirem ao aspecto da experiência puramente cotidiana, uma linguagem cotidiana, aparente, a forma de pensamento destes não se colocará acima do nível do pseudoconceito, presos à lógica formal, em outras palavras, complexos.

Ao abordar os conceitos dentro do pensamento de Vigotski, devemos subdividi-los, em conceitos $\operatorname{cotidianos}^{2}$ e científicos.

Os conceitos cotidianos são aqueles que nascem da comunicação direta do sujeito com o seu entorno imediato, oferecendo à criança dados puramente empíricos, adquiridos por meio da experiência imediata, não passando de noções gerais ou um estágio transitório entre o pensamento em complexo, os pseudoconceitos e os verdadeiros conceitos (VIGOTSKI, 2009; FACCI, 2004).

O desenvolvimento do conceito científico, por outro lado, pressupõe não só a combinação de vínculos associativos formados pela memória e a generalização de determinados elementos concretos da experiência, mais do que o simples hábito mental, mas também um processo contínuo de discriminação, a abstração e o isolamento de determinados elementos e, ainda, a habilidade de examinar esses elementos discriminados e abstraídos fora do vínculo concreto e fatual que permeiam a experiência prática (VIGOTSKI, 2009).

${ }^{2}$ Algumas vezes se encontra na literatura conceitos cotidianos e científicos 
Tais conceitos são apropriados por meio do processo educativo, da colaboração sistemática entre o professor e a criança, mediante a qual esta passa a ter acesso aos signos e ao desenvolvimento de novas formas de sistematização e das funções psicológicas superiores.

Nesse processo de desenvolvimento dos conceitos, sinalizamos o papel sine qua non desempenhado pela linguagem, pela palavra, uma vez que, conforme o já apresentado, por meio dela o indivíduo tem meios para dirigir deliberadamente sua atenção para determinados objetos ou atributos. Ao se servir delas, o indivíduo passa a ter acesso à simbolização e sintetização, características básicas do conceito abstrato, uma vez que este é utilizado como um signo (VIGOTSKI, 2009; LURIA, 1991).

Assim, destacamos o papel primordial da escola no processo de reprodução do ser social, uma vez que ela se configura como o lócus privilegiado para a apropriação dos instrumentos de trabalho e de domínio da conduta humana, em outros termos, um local que deve permitir a assimilação dos conhecimentos socialmente desenvolvidos, ao passo que desenvolve por meio do processo de humanização novas formas de raciocinar e compreender a realidade de uma forma mais ampla.

Seguindo a proposta de Vigotski (2009, p. 244), assinalamos que o conceito científico segue um caminho adverso em comparação ao conceito cotidiano, uma vez que: "pela definição verbal primária que, nas condições de um sistema organizado, descende ao concreto, ao fenômeno, ao passo que a tendência do desenvolvimento dos conceitos espontâneos se verifica fora do sistema, ascendendo para as generalizações." Dessa forma, ao chegar ao fenômeno já temos uma série de instrumentos que nos auxiliam a compreendê-lo gestado mediante a prática educativa. O conceito espontâneo, por outro lado, se produz fora de um sistema determinado, as "categorias" surgem por meio das generalizações de traços aparentes, algumas vezes se relacionando ao pensamento por complexo. Em outros termos, para Vigotski (2009, p. 244):

O curso do desenvolvimento do conceito científico nas ciências sociais transcorre sob as condições do processo educacional, que constitui uma forma original de colaboração sistemática entre o pedagogo e a criança, colaboração esta em cujo processo ocorre o amadurecimento das funções psicológicas superiores da criança com o auxílio e a participação do adulto. No campo do nosso interesse, isso se manifesta na sempre crescente relatividade do pensamento causal e no amadurecimento de um determinado nível de arbitrariedade do pensamento científico, nível esse criado pelas condições de ensino.

Por meio da escola e da prática docente, são ensinados aos sujeitos a formalização das regras da lógica e a forma de sua assimilação, envolvendo processos de análise, iniciados pela prática pedagógica, a qual nos auxilia nos processos de abstração e generalização. Os conceitos espontâneos, por sua vez, caracterizam-se pela ausência de uma percepção consciente, sendo orientados pelas semelhanças concretas e por generalizações isoladas (FACCI, 2004).

A linha que separa os conceitos espontâneos e científicos é muito tênue, uma vez que o desenvolvimento do conceito científico deve se apoiar em um conceito espontâneo já apropriado pelo indivíduo, e este não podendo ser indiferente ao indivíduo (FACCI, 2004). Para Luria (1994), esse processo de transição, de uma significação material/concreta do objeto, em direção a estruturas mais abstratas, configura-se como um processo de enriquecimento ou ascensão autêntica do concreto, uma vez que a perspectiva defendida pelo autor soviético compreende a concreticidade como a "riqueza das ligações em cujo sistema o conceito inclui o referido objeto." (LURIA, 1994, p. 36).

Assim, se a escola é o lugar privilegiado para a formação dos conceitos e o desenvolvimento das funções psicológicas superiores, permeadas pela linguagem, veículo da reprodução social, percebemos que a boa aprendizagem é aquela que conduz ao desenvolvimento, levando em consideração aquilo que o indivíduo já consegue fazer, quer por maturação biológica, quer pelo desenvolvimento dos pseudoconceitos, mas não deve se restringir a eles. Daí resulta que, a tomada de consciência proporcionada pela prática pedagógica faz com que o indivíduo desenvolva não apenas uma forma de pensar, mas sua ação se irradia para uma gama de searas diferentes, não desenvolvendo ou reforçando uma capacidade específica, mas diferentes faculdades que possam responder de forma mais adequada a esse problema (VIGOTSKI, 2009; VYGOTSKY, 2005). 


\section{CONCLUSÃO}

A partir do exposto até aqui, esperamos contribuir com a reflexão sobre a forma como as categorias trabalho e linguagem atuam no processo de humanização do homem e, consequentemente, na gênese da consciência humana. Destacamos a importância de se procurar essa resposta na base material, e assim conceber as categorias existentes no gênero humano à luz das relações que estes travam com sua generalidade. Dessa forma, ao retomar os postulados marxianos, descamamos a importância que o caráter instrumental exerce na transformação da realidade natural, em realidade humana, ao passo que atua no processo de humanização do gênero humano.

$\mathrm{Na}$ esteira dessas discussões, aportamos na categoria da linguagem, a qual pode ser tida como um instrumento do trabalho, desempenhando o papel de informar e auxiliar os sujeitos a se apropriem do mundo transformado pelo trabalho. Buscamos compreender que, de forma semelhante ao instrumento em uma relação de trabalho, temos o signo, que atua na operação psicológica, sendo um dos principais fatores no desenvolvimento das funções psicológicas superiores, as quais são as responsáveis por conferir a humanidade do homem, uma vez que elas nascem em meio às relações sociais. Ao retomar a relação entre trabalho e linguagem apontamos tanto para o processo de gênese da consciência, quanto à formação de conceitos.

Dessa maneira, o segundo momento de nosso estudo consistiu em caminhar das generalizações baseadas em traços concretos rumo ao abstrato, por meio do processo como Vigotski concebe a de formação de conceitos e, neste último, dos conceitos provenientes da esfera cotidiana para aqueles científicos.

Ressaltamos que, neste último aspecto, fomos movidos pela vontade, mas também pelo esforço e uma espécie de compromisso para com a própria educação/escola, uma vez que foi aqui onde conseguimos, por meio de Vigotski, apreender mais acerca da importância da escola, em especial o papel que o professor pode desempenhar na apropriação, por parte do homem, das riquezas, tanto material, quanto espiritual que lhe são devidas enquanto partícipes do gênero humano.

\section{REFERENCIAS}

DUARTE, N. Individualidade, conhecimento e linguagem na concepção dialética de desenvolvimento em Vigotski. Fórum Linguístico, v. 13, p. 1559-1571, 2016. Disponível em: https://periodicos.ufsc.br/index.php/forum/issue/view/2444. Acesso em: 20 abr. 2017.

ENGELS, F. Dialéctica de la naturaliza. 1983 Disponível em: http://archivo.juventudes.org/textos/Friedrich\%20Engels/Dialectica\%20de\%20la\%20Naturaleza.pdf. Acesso em: 15 jun. 2014.

FACCI, M. G. D. Valorização ou esvaziamento do trabalho do professor?: um estudo crítico-comparativo..., Campinas: Autores Associados, 2004.

GONCALVES, R. M. P.; JIMENEZ, S. V. Relações antagônicas entre sentido e significado do trabalho no capital: uma análise na perspectiva ontológica. Psicologia e Sociedade, Belo Horizonte, v. 25, n. 3, p. 685-694, 2013. Disponível em: http://www.scielo.br/scielo.php?script=sci arttext\&pid=S0102-71822013000300022\&lng=pt\&nrm=iso. Acesso em: 2 jun. 2017.

LEONTIEV, A. O desenvolvimento do psiquismo. São Paulo: Centauro, 2004.

LIMA, M. F.; JIMENEZ, S. V. O complexo da educação em Lukács: uma análise à luz das categorias trabalho e reprodução social. Educ. rev., Belo Horizonte, v. 27, n. 2, p. 73-94. 2011. Disponível em: http://www.scielo.br/scielo.php?script=sci arttext\&pid=S0102-46982011000200005\&lng=en\&nrm=iso..$\quad$ Acesso em: 08 jun. 2017. 
LOPES JUNIOR, A. D.; MORAES, B. M.; GONÇALVES, R. M. P. As contribuições de Vigotski para o cenário educacional brasileiro: as funções psicológicas superiores em foco. Educação em Perspectiva, v.8 n. 1, p. 72-88, 2017. Disponível em: https://educacaoemperspectiva.ufv.br/index.php/ppgeufv/article/view/802/202. Acesso em: 2 ago. 2017.

LUKÁCS, G. Para uma ontologia do ser social. São Paulo: Boitempo, 2013. v. 2.

LURIA, A. R. Pensamento e linguagem: as últimas conferências de Luria. Porto Alegre: Artes Médicas, 1986.

LURIA, A. R. Curso de psicologia. Rio de Janeiro: Civilização Brasileira, 1991.v. 1.

LURIA, A. R. Curso de psicologia. Rio de Janeiro: Civilização Brasileira, 1994. v. 4.

MARTINS, L. M. Desenvolvimento do pensamento e educação escolar: etapas de formação de conceitos à luz de Leontiev e Vigotski. Fórum Linguístico, v. 13, p. 1572-1586, 2016. Disponível em: https://periodicos.ufsc.br/index.php/forum/issue/view/2444. Acesso em: 20 abr. 2017.

MARX, K.; ENGELS, F. A ideologia alemã. Rio de Janeiro: Civilização Brasileira, 2007.

MARX, K. O capital: crítica da economia política. Rio de Janeiro: Civilização Brasileira, 2014. v. 1.

VIGOTSKI, L. S. A construção do pensamento e da linguagem. 2. ed. São Paulo: Martins Fontes, 2009.

VIGOTSKI, L. S. Obras escogídas: problemas del desarrollo de la psique. Tomo III. Madrid: Visor, 2012.

VYGOTSKY, L. S. Aprendizagem e desenvolvimento intelectual na idade escolar. In. LEONTIEV. A. [et. al], Psicologia e Pedagogia: bases psicológicas da aprendizagem e do desenvolvimento, São Paulo, Centauro, 2005.

\section{()(1) $\circledast \Theta$}

